\title{
Biological Networks Governing the Acquisition, Maintenance, and Dissolution of Pluripotency: Insights from Functional Genomics Approaches
}

\author{
Kevin Andrew Uy Gonzales ${ }^{1}$ And Huck-Hui NG ${ }^{1,2,3,4}$ \\ ${ }^{1}$ Stem Cell and Regenerative Biology, Genome Institute of Singapore, Singapore 138672, Singapore \\ ${ }^{2}$ Department of Biochemistry, National University of Singapore, Singapore 117597, Singapore \\ ${ }^{3}$ Department of Biological Sciences, National University of Singapore, Singapore 117597, Singapore \\ ${ }^{4}$ School of Biological Sciences, Nanyang Technological University, Singapore 639798, Singapore \\ Correspondence:nghh@gis.a-star.edu.sg
}

\begin{abstract}
The repertoire of transcripts encoded by the genome contributes to the diversity of cellular states. Functional genomics aims to comprehensively uncover the roles of these transcripts to reconstruct biological networks and transform this information into useful knowledge. High-throughput functional screening has served as a powerful genetic discovery tool by enabling massively parallel implementation of biological assays. In recent years, high-throughput screening has unearthed crucial players in the regulation of different aspects of pluripotency, which is a unique property that enables a cell to differentiate into multiple cell types of the three major lineages. Pluripotency thus represents an interesting biological paradigm for studying the acquisition, maintenance, and dissolution of cellular states. In this review, we highlight the major findings of high-throughput studies to dissect these three aspects of pluripotency for the mouse and human systems. Collectively, they provide new insights into cell fate maintenance and transition. In addition, we also discuss the opportunities and challenges awaiting highthroughput screening in the future.
\end{abstract}

The human genome is comprised of more than 20,000 protein-coding genes and even more of noncoding RNAs and regulatory sequences, most of which are postulated to contribute to various cellular processes. Uncovering the roles of these genetic elements is the goal of functional genomics, to understand biological mechanisms and transform this knowledge into practical applications. Many tools have been used to study gene and protein function, including gain-of-function and loss-of-function screens. In fact, initial screens have led to fundamental discoveries on the cell cycle (Hartwell 1967), embryonic development (Nusslein-Volhard and Wieschaus 1980), and vesicular trafficking (Novick et al. 1980). However, early research has mostly allowed inspection of a limited number of factors of interest at a time, making it difficult to comprehensively assign the biological function of all factors derived from the genome. In more recent years, technological innovations have facilitated the implementation of experiments in a high-throughput manner, which was immediately applied to chemical libraries for drug discovery (Pereira and Williams 2007). Subsequently, the development of genetic techniques such as RNA interference (RNAi) (Fire et al. 1998) and traceable mutagenesis (Liu et al. 2000) enabled the application of high-throughput technology to genetic assays, accelerating the advancement of functional genomics.

High-throughput functional screening (HTFS) is the large-scale discovery of the roles of molecular factors in the context of defined biological processes. To accomplish this, rigorous development and optimization of the experimental techniques used are necessary such that they can be reproducibly and robustly executed en masse. With a well-designed HTFS procedure, the functional relevance of a plethora of compounds or genes in modulating a specific phenotype can be effectively and systematically identified. In addition, compared with other experiments that yield large correlative data sets such as epigenomics, transcriptomics, and proteomics, HTFS enables deterministic assignment of causative experimental variables to resulting phenotypes. Thus, the utility and flexibility of HTFS have propelled it to be widely used as a method of choice for the systematic discovery of novel biological players across many scientific fields. This review focuses on the application of HTFS approaches to understand the biological properties of pluripotent stem cells, and how it refined our grasp of the intricate machineries behind the acquisition, maintenance, and dissolution of cellular states.

\section{PLURIPOTENCY AND PLURIPOTENT CELL MODELS}

Past studies of early development heavily relied on animal models wherein it is practical to extrinsically manipulate developmental processes at any embryonic stage. An in vitro alternative to study development was achieved on the derivation of embryonic stem cells (ESCs) from the inner cell mass of blastocyst-stage embryos (Evans and Kaufman 1981; Martin 1981; Thomson 
et al. 1998; Cowan et al. 2004). ESCs are capable of indefinite self-renewal in an undifferentiated state in vitro. They also harbor the developmental potency to give rise to every cell type in the embryo proper and are thus called pluripotent. These properties of ESCs make them ideal for regenerative medicine and drug testing applications. Importantly, ESCs serve as a cellular platform for dissecting the multitude of factors and pathways that govern pluripotency, therefore acting as an in vitro model for studying early development and cell fate decisions. As such, numerous studies have participated in scrutinizing the intricate machinery underlying the ESC state.

The most studied ESC cultures are those derived from mice and humans. Although both mouse and human ESCs share fundamental properties such as pluripotency and self-renewal capacity, they show stark differences such as those in signaling requirements, gene expression patterns, and morphology. Hence, they are considered to exist in distinct pluripotent states. Although mouse ESCs (mESCs) are considered to be "naïve," that is harboring properties resembling preimplantation epiblast cells, human ESCs (hESCs) belong to the "primed" state, which instead is closer to the later postimplantation epiblast (Nichols and Smith 2009). Nevertheless, the primed pluripotent state can also be captured from mouse, as represented by epiblast stem cells (EpiSCs) (Brons et al. 2007; Tesar et al. 2007), and there has been great effort in deriving naïve human pluripotent cells (Chan et al. 2013; Gafni et al. 2013; Takashima et al. 2014; Theunissen et al. 2014; Ware et al. 2014). Understanding the regulatory networks governing these distinct states, and transitions between them, is fundamental to the understanding of embryonic cellular states.

\section{Molecular Dissection of the Maintenance of Pluripotent States}

Earlier works using HTFS to study the regulation of pluripotency were implemented in the then-established mESC culture. RNAi HTFS was widely used to search for pivotal modules for mESC self-renewal (Fig. 1A). The first study by Lemischka's group revealed the importance of Tbx3, Tcl1, and Esrrb, which acted together in a functional network distinct from the Oct4-Sox2-Nanog cluster (Ivanova et al. 2006). Thereafter, several RNAi screens have been performed, discovering various novel factors and complexes important for the sustenance of the mESC state, such as the Tip60-p400 complex (Fazzio et al. 2008), Pafl complex (Ding et al. 2009), Cnot3 and Trim 28 of the c-Myc cluster (Hu et al. 2009), the mediator and cohesin complexes (Kagey et al. 2010), and ubiquitin-proteasome system (UPS) members like Psmd14 (Buckley et al. 2012).

Although HTFS has been widely applied to mESCs to identify critical self-renewal factors, there has been a deficiency in knowledge about the regulatory network of EpiSCs. This gap was only filled by a very recent study looking at modulators of Oct4 expression in EpiSCs using RNAi HTFS (Fig. 1A; Ding et al. 2015). The screen validated many pluripotency maintenance factors observed in former HTFSs on mESCs, revealing a large overlap in the regulatory networks of mESC and EpiSC self-renewal (Fig. 1B). Strikingly, the results suggest that certain known regulators such as the cohesin complex, the Tip60p400 complex, and the Myc cluster maintain EpiSC identity by repressing Oct4 expression, in stark contrast to mESCs, wherein these factors up-regulate Oct4 and other pluripotency genes (Ding et al. 2015). This HTFS study therefore sheds light on the diverse regulatory mechanisms of the mESC and EpiSC states; although many factors are shared, they are wired differently into the pluripotency network.

RNAi HTFS was similarly exploited for the genomewide identification of regulators of human pluripotent state maintenance (Chia et al. 2010). Using this approach, new players such as the transcription factors PRDM14 and NFRKB, as well as the INO80 and COP9 complexes, have been discovered to function in hESC self-renewal (Fig. 1A). Moreover, this study revealed crucial factors for the maintenance of pluripotency that are conserved with mouse, which can thus be regarded as universal regulators of self-renewal (Fig. 1B). Nonetheless, many of the hits were unique to human ESCs, highlighting the importance of species-specific differences in the network regulating pluripotency. It will be of interest to perform a similar screen on naïve hESCs to determine the changes in the wiring of the pluripotency circuitry in the human naïve state.

Finally, HTFS has also been used in the search for molecules that can maintain hESC self-renewal (Fig. 1A). For example, a secretory proteome screen using gain-of-function HTFS was performed on hESCs, discovering that the pigment epithelium-derived factor can promote long-term maintenance of hESCs without supplementation of standard hESC self-renewal factors (Gonzalez et al. 2010). Chemical HTFS has also been applied to hESCs by Studer's group, leading to the identification of certain small molecules like gatifloxacin that maintain hESC self-renewal in short term, as well as some that promote lineage-specific differentiation (Desbordes et al. 2008).

\section{Molecular Dissection of Induced Pluripotency}

During normal development, pluripotent cells differentiate toward cell fates of more restricted potency. However, even with terminally differentiated cell types such as fibroblasts, a pluripotent state can be induced through the introduction of defined transcription factors (Takahashi and Yamanaka 2006; Takahashi et al. 2007). Differentiated cells undergo complex transcriptional and epigenetic reprogramming to become induced pluripotent stem cells (iPSCs), which are generally believed to be equivalent to ESCs. Apart from measuring the molecular changes during reprogramming to map out its key steps, the complex reprogramming process can be dissected using a functional genetics approach (Fig. 2).

The earliest application of HTFS to reprogramming was using a focused RNAi library to determine regulators 
A

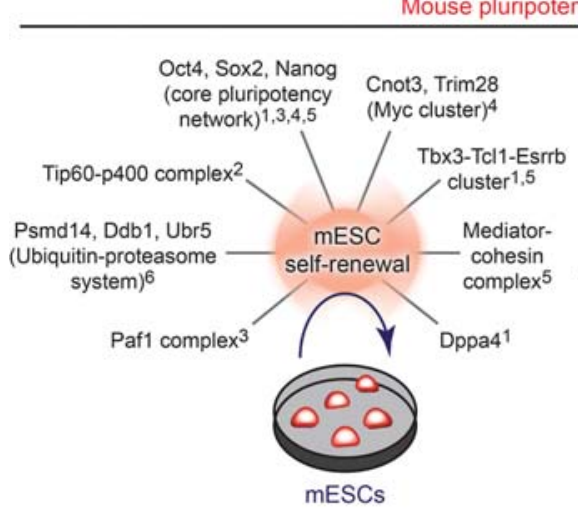

B

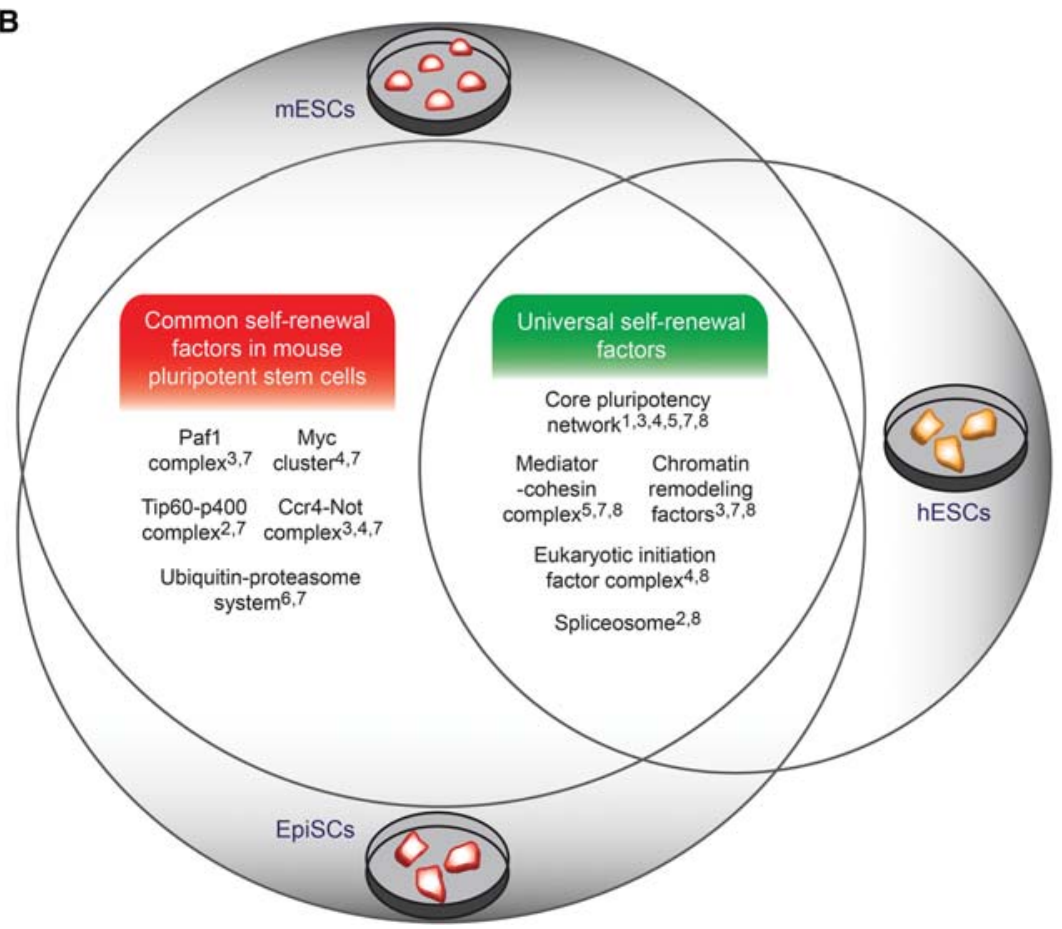

Human pluripotent stem cells
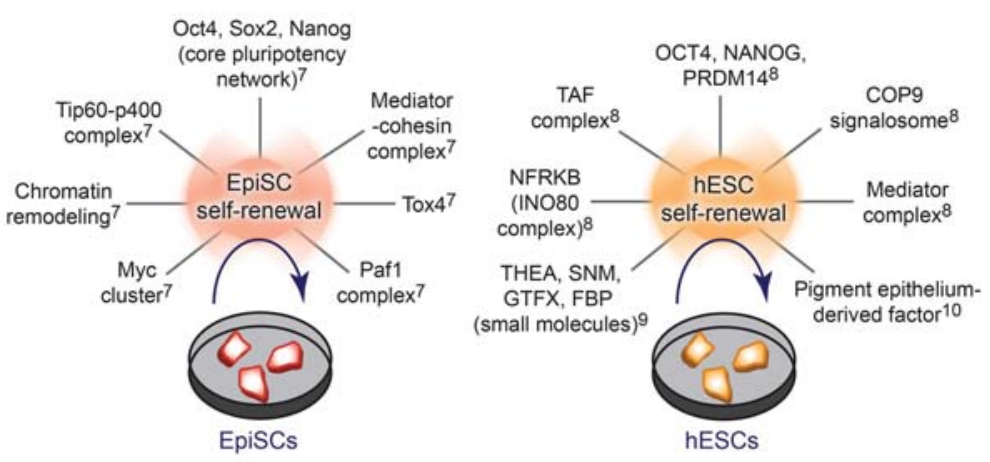

References:

1 Ivanova et al. 2006. Nature 442: 533-8

2 Fazzio et al. 2008. Cell 134: 162-74

3 Ding et al. 2009. Cell Stem Cell 4: 403-15

4 Hu et al. 2009. Genes Dev 23: 837-48

5 Kagey et al. 2010. Nature 467: 430-5

${ }^{6}$ Buckley et al. 2012. Cell Stem Cell 11: 783-98

7 Ding et al. 2015. Cell Systems 1: 141-51

8 Chia et al. 2010. Nature 468: $316-20$

9 Desbordes et al. 2008. Cell Stem Cell 2: 602-12

10 Gonzalez et al. 2010. PNAS 107: 3552-7

Figure 1. The functional network regulating the maintenance of pluripotent states. $(A)$ Regulators of self-renewal in mouse embryonic stem cells (mESCs), epiblast stem cells (EpiSCs), and human embryonic stem cells (hESCs) revealed by high-throughput functional screening (HTFS). (B) Common factors in the maintenance of mouse pluripotency and universal regulators of self-renewal across mouse and human pluripotent stem cells, as identified by HTFS.

of the initiation of reprogramming to mouse iPSCs (Samavarchi-Tehrani et al. 2010). Through this work, the importance of the mesenchymal-to-epithelial transition (MET) in early reprogramming was uncovered, and it was found that bone morphogenetic protein (BMP) signaling enhances iPSC derivation by promoting MET via miR-200 (Fig. 2A). RNAi HTFS was similarly used in human cells to define the barriers to reprogramming toward pluripotency (Qin et al. 2014), wherein several processes including ubiquitination, endocytosis, and cell adhesion and motility were identified (Fig. 2B).

Although the aforementioned studies are important contributions to the field, their observations are based on a loss-of-function analysis applied at the start of the reprogramming process. However, reprogramming is a complex and progressive process that is subdivided into distinct stages (Brambrink et al. 2008; Stadtfeld et al. 2008; Samavarchi-Tehrani et al. 2010). To systematically dissect the reprogramming process, Rana's group performed an elegant RNAi HTFS on mouse fibroblasts undergoing various stages of reprogramming (Yang et al. 2014). They found that core pluripotency genes as well as phosphoinositol-3-kinase and calcium signaling were crucial for the early phases, whereas cell cycle and cytoskeletal factors are focal for later stages (Fig. 2A). Furthermore, many nondifferentially expressed genes were found to affect the reprogramming process, raising the notion that genes with stable expression levels actively 
A

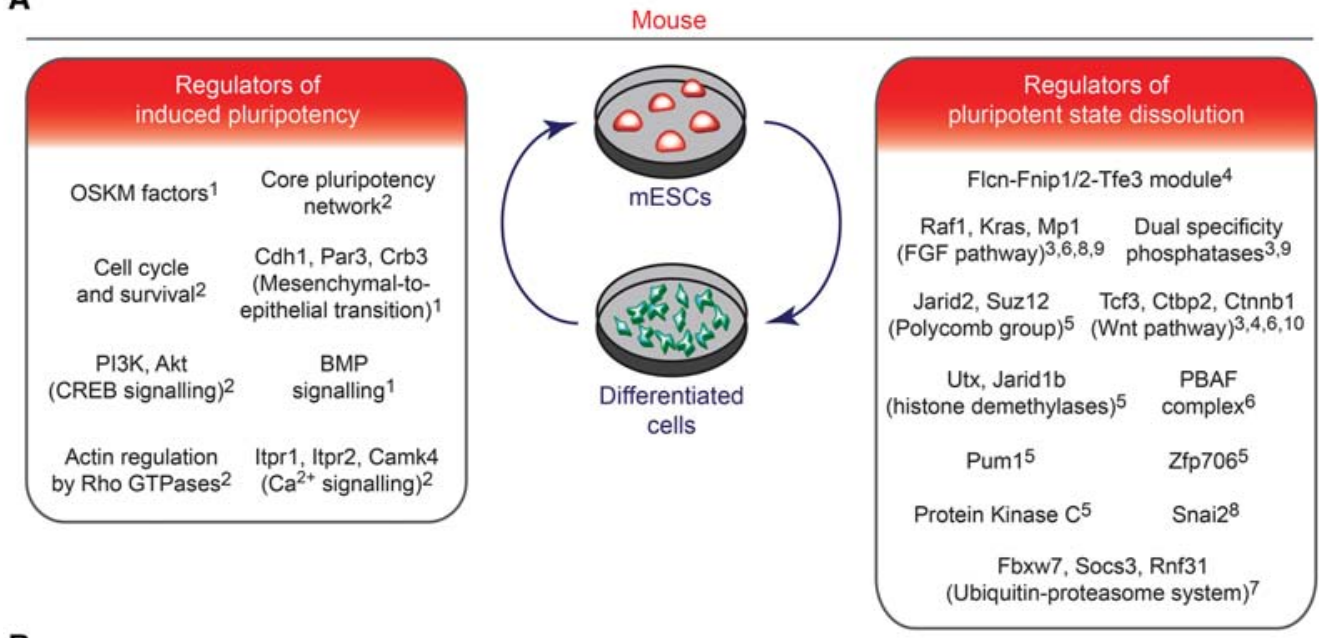

B

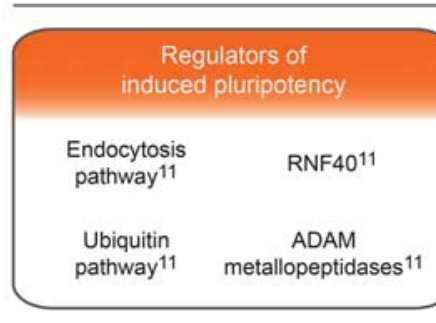

References:
1 Samavarchi-Tehrani et al. 2010. Cell Stem Cell 7: 64-77
2 Yang et al. 2014. Cell Rep 8: 327-37
3 Yang et al. 2012. PLoS Genet 8: e1003112
4 Betschinger et al. 2013. Cell 153: 335-47
5 Leeb et al. 2014. Cell Stem Cell 14: 385-93
6 Schaniel et al. 2009. Stem Cells 27: 2979-91
7 Buckley et al. 2012. Cell Stem Cell 11: 783-98
8 Gingold et al. 2014. Mol Cell 56: 140-52
9 Westerman et al. 2011. J Exp Med 208: 2675-89
10 Guo et al. 2011. PLoS One 6: e18189
11 Qin et al. 2014. Cell 158: 449-61
12 Gonzales et al. 2015. Cell 162: $564-79$
13 Gayle et al. 2015. Stem Cell Rep 4: $926-38$

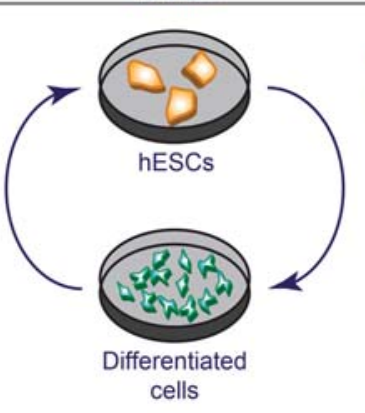

cells

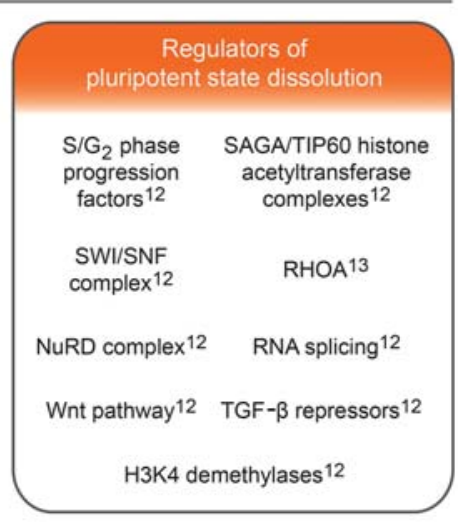

H3K4 demethylases ${ }^{12}$

Figure 2. The functional network regulating the acquisition and dissolution of pluripotency. Regulators of reprogramming and pluripotent state dissolution in $(A)$ mouse and $(B)$ human systems determined by HTFS.

participate in cell fate transitions (Yang et al. 2014). Notably, the same group has also performed chemical screening to identify reprogramming-enhancing molecules such as as p38 inhibitors and Aurora A kinase inhibitors (Li and Rana 2012).

Finally, HTFS has been applied to the reprogramming of primed pluripotent states to naivety. In a forward genetic screen employing piggyBac transposition to randomly activate endogenous gene expression, the orphan nuclear receptors $\mathrm{Nr} 5 \mathrm{a} 1$ and $\mathrm{Nr} 5 \mathrm{a} 2$ were identified to potently facilitate reprogramming of EpiSCs to mESClike cells (Guo and Smith 2010). More recently, Jaenisch and colleagues have used chemical HTFS to find small molecules that support the self-renewal of a naïve hESC state by using a fluorescence reporter driven by the endogenous POU5F1 distal enhancer, which is dominantly active in naïve ESCs (Theunissen et al. 2014). Their
HTFS study led to the development of an inhibitor cocktail that induces and maintains hESCs with naïve properties, adding another formula among the search for naïve hESCs (Chan et al. 2013; Gafni et al. 2013; Takashima et al. 2014; Ware et al. 2014).

\section{Molecular Dissection of the Dissolution of Pluripotent States}

Although studying the maintenance and acquisition of pluripotency are critical in harnessing the potential of ESCs, unraveling the process of differentiation is also important for the complete understanding of pluripotent stem cell biology. The process of differentiation from ESCs can be conceptually subdivided into two major steps (Gonzales et al. 2015). More commonly studied is 
"lineage specification," which is the assembly of a new regulatory program corresponding to a specific somatic cell fate. Conversely, there is a lack of knowledge on "pluripotent state dissolution" (PSD), which is the shutting down of the pluripotent transcriptional network at the onset of differentiation.

In this regard, Smith and colleagues have performed HTFSs to identify factors regulating PSD from groundstate mESCs (Fig. 2A) cultured under MEK (MAPK/ ERK kinase) and GSK3 inhibition (widely known as $2 i)$. In their first study, they dissected PSD by withdrawal of the $2 i$ molecules together and individually (Yang et al. 2012). Here, they uncovered the role of dual specificity phosphatases in regulating PSD through ERK (extracellular signal-related kinase) signaling. Subsequently, they executed another RNAi HTFS in ground-state mESCs undergoing PSD by $2 i$ withdrawal, and found that exclusion of the transcription factor Tfe 3 from the nucleus is essential for effective PSD (Betschinger et al. 2013). Most recently, they similarly explored PSD in haploid mESCs through a piggyBac mutagenesis approach, and identified a role for Zfp706 and Pum1 in the exit from pluripotency (Leeb et al. 2014).

Several other groups have also engaged HTFS approaches to explore PSD of mESCs in the context of other differentiation induction cues (Fig. 2A). Using RNAi libraries targeting chromatin regulators (Schaniel et al. 2009) and UPS members (Buckley et al. 2012), the PBAF (polybromo-associated BRG1-associated factor) chromatin remodeling complex and E3 ligase Fbxw were respectively found to be crucial for the repression of Nanog and other pluripotency factors during retinoic acid (RA)-induced PSD. These focused screens were extended by Wang's group using a genome-wide RNAi library (Gingold et al. 2014). Aside from validating known regulators of pluripotency, they found opposing effects of Snai1 and Snai2 on Nanog expression; although Snai1 knockdown enhanced PSD, Snai2 knockdown prevented it. They also related their findings to reprogramming and discovered that Snail cooperates with Nanog to enhance iPSC derivation, whereas Snai2 antagonizes this process (Gingold et al. 2014). On the other hand, Westerman et al. (2011) performed a genome-wide RNAi HTFS examining PSD by leukemia inhibitory factor withdrawal, and found that loss of function of the scaffolding protein Mp1 can block mESC differentiation. Finally, mutagenesis HTFS has been applied to mESCs undergoing neural differentiation induced using N2B27 medium (Guo et al. 2011). In this assay, piggyBac gene traps were introduced to Blm-deficient mESCs, which experience frequent loss of heterozygosity, leading to the finding that Tcf3 knockout enhanced self-renewal and prevented PSD in mESCs. Looking at these studies altogether, it can be inferred that particular pathways such as the Wnt and FGF pathways regulate PSD in mESCs under various contexts, whereas others are only effective under specific differentiation cues.

There are molecular and cellular differences between mouse and human ESCs. For instance, mouse and human ESCs rely on different cytokines and signaling pathways to maintain pluripotency (Niwa et al. 1998; Ying et al. 2003, 2008; Beattie et al. 2005; Xu et al. 2005). Therefore, an imperative experiment is to map out the pathways that govern PSD in hESCs. Addressing this issue, Ng's group conducted an RNAi screening study in hESCs under five distinct differentiation conditions to identify molecular pathways regulating PSD de novo (Gonzales et al. $2015)$. In the first four conditions, major signals imposing hESC self-renewal (namely TGF- $\beta$, MEK, and PI3K signaling) were individually or collectively withdrawn, whereas the fifth condition induced PSD by introduction of a differentiation signal in the form of RA. Data from this multiconditional screen support the presence of universal and context-specific regulators of PSD. Specifically, common gatekeepers of PSD in hESCs include histone acetyltransferase (HAT) complexes and the SWI/SNF complex, whereas context-dependent gatekeepers of PSD comprise RNA splicing and certain developmental pathways (Fig. 2B; Gonzales et al. 2015). Whereas some genes such as TCF3, TRRAP, and ARIDIA are conserved in mouse, most factors identified have not been implicated in PSD hitherto. Hence, similar to the regulation of selfrenewal, species-specific differences are evident in the regulation of PSD. Importantly, a strong enrichment of cell cycle hits was observed in this screen, specifically clustering in the $S$ and $G_{2}$ phases, leading to the discovery of $S$ and $G_{2}$ phase-specific pathways that deterministically restrict PSD (Gonzales et al. 2015). A complementary gain-of-function HTFS using the piggyBac transposon mutagenesis system was also implemented to search for factors that can block RA-induced differentiation in cooperation with NANOG (Gayle et al. 2015); this study discovered that DENND2C negatively regulates RHOA (Ras homolog family member A) activity by interfering with RHOA's DNA binding and by promoting its export out of the nucleus.

\section{Insights into the Biology of Pluripotency}

Characterization of molecular networks controlling pluripotency using functional genomics approaches has provided useful insights in understanding cell fate maintenance and transitions. First, from the molecular dissection of the maintenance of pluripotent states, the roles of universal effectors of self-renewal such as the core pluripotency network and chromatin remodeling were revealed (Fig. 1B). Moreover, although there is a significant overlap in the regulatory networks of mESCs and EpiSCs (Fig. 1B), many self-renewal factors differ between mouse and human pluripotent states. This suggests that species-specific disparities greatly distinguish the networks governing self-renewal of discrete pluripotent states. In contrast, primed and naïve pluripotent states of the same species are set apart by alternative functions of self-renewal factors, exemplified by the opposite regulation of Oct4 expression by common mouse self-renewal effectors such as Tip60p400 complex and the Myc cluster (Ding et al. 2015). Hence, functional genomics studies on pluripotency maintenance cooperatively provide insight on the diversity of regulatory circuitries across different cellular states. 
From the molecular dissection of induced pluripotency, the numerous effectors and barriers to reprogramming in both mouse and human systems were identified (Fig. 2). Additionally, although many transcriptomic studies focus on differentially expressed genes as an indication of functional relevance, studies on reprogramming teach that genes with stable expression levels such as Nobox and Nfe 2 can actively participate in cell fate transitions (Yang et al. 2014). These studies also show the multiplicity in the control of extensive processes like reprogramming, wherein distinct modules are crucial for the early and late phases (Yang et al. 2014). Therefore, the functional examination of reprogramming reaffirmed the concept of multifaceted regulation of complex phenomena such as those in cell fate decisions.

Finally, the molecular dissection of PSD highlights the existence of both universal and context-dependent regulators for cell fate decisions (Fig. 2). Pathways such as Wnt (int/Wingless) and FGF (fibroblast growth factor) in mouse, as well as complexes such as SWI/SNF and SAGA/TIP60 HATs in human, generally facilitate PSD under various signals. On the contrary, histone demethylation and splicing seem to affect PSD only when induced by specific differentiation cues (Leeb et al. 2014; Gonzales et al. 2015). These findings emphasize the importance of assigning molecular function under appropriate contexts, as many factors play distinct roles contingent on environmental cues and cross talk with other pathways. Moreover, screening data sets on PSD recurrently suggest that highly homologous genes, such as Snail versus Snai2 and SMARCC1 versus SMARCC2, can play opposite functions in cell fate transitions (Gingold et al. 2014; Gonzales et al. 2015).

The various insights on cell fate regulation obtained from studies described above show the success of applying HTFS to pluripotent stem cell biology. This approach likewise uncovered many novel factors and pathways crucial for the acquisition, maintenance, and dissolution of pluripotency (Figs. 1 and 2), including fundamental processes such as MET for reprogramming initiation (Samavarchi-Tehrani et al. 2010) and mediator-cohesin activity for self-renewal (Chia et al. 2010; Kagey et al. 2010; Ding et al. 2015). Furthermore, screening in ESCs has led to the development of novel methods for the induction and maintenance of pluripotent cell fates (Gonzalez et al. 2010; Theunissen et al. 2014). All in all, these works provide a foundation for future examination of stem cells and cell fate decisions.

\section{Modeling Basic Biological Processes in Pluripotent Stem Cells}

ESCs have also been used as tools to perform HTFS investigating other cellular processes besides pluripotency. For instance, gene trap-based mutagenesis HTFS on haploid mESCs (Elling et al. 2011) and Cas9-based mutagenesis HTFS on diploid mESCs (Koike-Yusa et al. 2014) have been used to examine novel genes implicated in resistance to toxin-induced cell death. Exploiting Xistinduced lethality in haploid mESCs and combining it with gene trap-mutagenesis HTFS has also facilitated the discovery of the role of the RNA-binding protein Spen in $X$ inactivation (Monfort et al. 2015). A very recent study used mESCs to reveal multiple pathways and interactions responsible for retroviral element silencing, including those of histone chaperones and sumoylation factors (Yang et al. 2015). Hence, the applicability of ESCs for HTFS assays is not limited to studying pluripotency, as their established culture and unique properties can be exploited to explore diverse biological processes.

\section{THE FUTURE OF HTFS}

Although HTFS traditionally relies on RNAi, ectopic gene expression, or chemical inhibition, there are emerging technologies that will inevitably transform unbiased and parallel screening approaches. In this section, we discuss the potential applications of new approaches and systems that will enable the study of global regulation of biological systems.

\section{CRISPR/Cas9 HTFS}

A new emerging method to conduct HTFS is by using programmable nucleases that can modify DNA in a sequence-specific manner. Specifically, the adaptation of microbial endonuclease Cas9 for gene editing purposes (Cong et al. 2013; Mali et al. 2013) has enabled targeted mutagenesis to be performed on a high-throughput scale. Because Cas 9 specificity is guided by nucleotide complementation by the clustered regularly interspaced short palindromic repeat (CRISPR), it can be easily designed to target most loci in the genome.

Numerous studies have shown that this incipient technique can be robustly adapted to a HTFS platform (Koike-Yusa et al. 2014; Shalem et al. 2014; Wang et al. 2014). Moreover, the Cas 9 nuclease has been modified to act as transcriptional activators or repressors, thus also enabling gain-of-function and nonmutagenic loss-offunction HTFS with the same library of guide RNAs (Gilbert et al. 2014; Konermann et al. 2015). In addition, Cas 9 can be designed to target regulatory sequences in addition to transcribed regions, allowing HTFS to be applied in probing epigenetics and trans-regulation. These features of CRISPR/Cas9 HTFS provide systematic modification of gene expression in various ways that cannot be achieved by any preceding HTFS methods.

CRISPR/Cas9 screening bodes to be a valuable tool for discovery of gene function surpassing its predecessors. However, this method is still in its infancy, and critics have raised concerns on the efficiency and specificity of the system (Fu et al. 2013; Hsu et al. 2013; Kuscu et al. 2014). Nevertheless, there are already emerging methods and modifications to improve CRISPR/Cas9 targeting (Ran et al. 2013; Cho et al. 2014; Fu et al. 2014; Guilinger et al. 2014; Tsai et al. 2014). Given the technique's versatility and ongoing efforts for its improvement, it is highly likely that CRISPR/Cas9 screening will be widely used in the near future in diverse fields of study. 


\section{In Vivo HTFS}

Although HTFS is more readily applicable to in vitro cell culture systems, functional screening has long been used in vivo in more primitive organisms, such as nematodes, flies, and zebrafish, wherein it was pragmatic to apply distinct treatments into each individual in a large-scale yet traceable way (Patton and Zon 2001; Jorgensen and Mango 2002; St Johnston 2002; Pardo-Martin et al. 2010).

Following up from these studies, functional screening has been innovatively adopted for mammalian systems. Using RNAi technology, different cells within the same animal can receive distinct manipulations that were made trackable by sequencing. This was predominantly performed in mouse cancer models, by introduction of RNAi into specific cell types before transplantation (Zender et al. 2008; Bric et al. 2009; Meacham et al. 2009). More recently, the development of techniques to deliver RNAi constructs inside specific organs has enabled direct in vivo screening in mice. These include the use of hydrodynamic tail vein injection for the liver (Wuestefeld et al. 2013; Rudalska et al. 2014), and ultrasound-guided in utero microinjections for the skin (Beronja et al. 2013; Schramek et al. 2014). Importantly, although limits in scalability have restricted earlier in vivo functional RNAi screens, contemporary studies have shown the feasibility of genome-wide RNAi HTFS in vivo (Beronja et al. 2013; Meacham et al. 2015). Finally, genomewide CRISPR/Cas9 HTFS is also now available for in vivo screening (Chen et al. 2015) and organism-level screening (Zhong et al. 2015) in mice.

Examination of function in the natural in vivo context is of course the ideal scenario for geneticists. However, technical difficulties such as construct delivery into specific organs remain the chief limitation for direct in vivo HTFS. For now, transplantation methods are the only option except for organs such as the skin and liver. Nevertheless, in vivo HTFS promises a positive prospect for dissection of genetic function in their native environment.

\section{HTFS on Organoids}

Although in vivo HTFS faces significant hurdles before broadening its application, a closer and very attractive alternative is the adaptation of organoid technology for HTFS. Organoids are defined as three-dimensional tissue cultures consisting of two or more cell types that possess organization and function resembling a specific organ (Lancaster and Knoblich 2014). These are typically differentiated from stem or progenitor cells to induce selforganization in a fashion similar to in vivo development. To date, various groups have shown the generation of several organoid models, including that of the gut (Sato et al. 2009), liver (Huch et al. 2013; Takebe et al. 2013), and brain (Lancaster et al. 2013). These in vitro organ models give unprecedented access to manipulating organ function that can be used for HTFS.

Such utility has been showed on tumor organoids; drug sensitivity screening on colorectal cancer organoids (van de Wetering et al. 2015) and breast cancer organoids
(Walsh et al. 2014) have been shown with good reproducibility. Albeit done only in low- to medium-throughput, these vanguard studies provide the first step into the development of organoid HTFS platforms. Several issues uniquely imposed by organoid culture however remain (Astashkina and Grainger 2014), and the challenge now is to address these concerns by optimizing screening methods before organoid HTFS can become a robust option for disease modeling and drug discovery.

\section{CONCLUSION}

The regulatory machineries behind the maintenance of and transitions between cellular states are complex. Understanding these intricate circuitries has been augmented by studies applying HTFS to pluripotent stem cells, which we have presented in this review. These studies not only reveal novel nodes of control in the acquisition, maintenance, and dissolution of pluripotency but also provide important insights that expand our understanding of the multifaceted regulations behind cell fate decisions. Furthermore, this molecular dissection of the functional genetics of pluripotency lays down the foundation for realizing pluripotent stem cell applications. With the emergence of new genetic tools such as CRISPR/Cas9 and new disease models based on iPSC and organoid technologies, HTFS approaches will certainly advance the discovery of novel molecules and pathways and, ultimately, the understanding of molecular functions in biology.

\section{ACKNOWLEDGMENTS}

We thank Friedrich Sachs, Iwona Szczerbinska, and Hongqing Liang for critical comments on the manuscript.

\section{REFERENCES}

Astashkina A, Grainger DW. 2014. Critical analysis of 3-D organoid in vitro cell culture models for high-throughput drug candidate toxicity assessments. Adv Drug Deliv Rev 69-70: $1-18$.

Beattie GM, Lopez AD, Bucay N, Hinton A, Firpo MT, King CC, Hayek A. 2005. Activin A maintains pluripotency of human embryonic stem cells in the absence of feeder layers. Stem Cells 23: 489-495.

Beronja S, Janki P, Heller E, Lien WH, Keyes BE, Oshimori N, Fuchs E. 2013. RNAi screens in mice identify physiological regulators of oncogenic growth. Nature 501: 185-190.

Betschinger J, Nichols J, Dietmann S, Corrin PD, Paddison PJ, Smith A. 2013. Exit from pluripotency is gated by intracellular redistribution of the bHLH transcription factor Tfe3. Cell 153: $335-347$.

Brambrink T, Foreman R, Welstead GG, Lengner CJ, Wernig M, Suh H, Jaenisch R. 2008. Sequential expression of pluripotency markers during direct reprogramming of mouse somatic cells. Cell Stem Cell 2: 151-159.

Bric A, Miething C, Bialucha CU, Scuoppo C, Zender L, Krasnitz A, Xuan Z, Zuber J, Wigler M, Hicks J, et al. 2009. Functional identification of tumor-suppressor genes through an in vivo RNA interference screen in a mouse lymphoma model. Cancer Cell 16: 324-335.

Brons IG, Smithers LE, Trotter MW, Rugg-Gunn P, Sun B, Chuva de Sousa Lopes SM, Howlett SK, Clarkson A, Ahrlund-Richter L, Pedersen RA, et al. 2007. Derivation of plu- 
ripotent epiblast stem cells from mammalian embryos. Nature 448: $191-195$.

Buckley SM, Aranda-Orgilles B, Strikoudis A, Apostolou E, Loizou E, Moran-Crusio K, Farnsworth CL, Koller AA, Dasgupta R, Silva JC, et al. 2012. Regulation of pluripotency and cellular reprogramming by the ubiquitin-proteasome system. Cell Stem Cell 11: 783-798.

Chan YS, Goke J, Ng JH, Lu X, Gonzales KA, Tan CP, Tng WQ, Hong ZZ, Lim YS, Ng HH. 2013. Induction of a human pluripotent state with distinct regulatory circuitry that resembles preimplantation epiblast. Cell Stem Cell 13: 663-675.

Chen S, Sanjana NE, Zheng K, Shalem O, Lee K, Shi X, Scott DA, Song J, Pan JQ, Weissleder R, et al. 2015. Genome-wide CRISPR screen in a mouse model of tumor growth and metastasis. Cell 160: 1246-1260.

Chia NY, Chan YS, Feng B, Lu X, Orlov YL, Moreau D, Kumar P, Yang L, Jiang J, Lau MS, et al. 2010. A genome-wide RNAi screen reveals determinants of human embryonic stem cell identity. Nature 468: 316-320.

Cho SW, Kim S, Kim Y, Kweon J, Kim HS, Bae S, Kim JS. 2014. Analysis of off-target effects of CRISPR/Cas-derived RNA-guided endonucleases and nickases. Genome Res 24: $132-141$.

Cong L, Ran FA, Cox D, Lin S, Barretto R, Habib N, Hsu PD, Wu X, Jiang W, Marraffini LA, et al. 2013. Multiplex genome engineering using CRISPR/Cas systems. Science 339: 819823.

Cowan CA, Klimanskaya I, McMahon J, Atienza J, Witmyer J, Zucker JP, Wang S, Morton CC, McMahon AP, Powers D, et al. 2004. Derivation of embryonic stem-cell lines from human blastocysts. N Engl J Med 350: 1353-1356.

Desbordes SC, Placantonakis DG, Ciro A, Socci ND, Lee G, Djaballah H, Studer L. 2008. High-throughput screening assay for the identification of compounds regulating self-renewal and differentiation in human embryonic stem cells. Cell Stem Cell 2: 602-612.

Ding L, Paszkowski-Rogacz M, Nitzsche A, Slabicki MM, Heninger AK, de Vries I, Kittler R, Junqueira M, Shevchenko A, Schulz H, et al. 2009. A genome-scale RNAi screen for Oct4 modulators defines a role of the Pafl complex for embryonic stem cell identity. Cell Stem Cell 4: 403-415.

Ding L, Paszkowski-Rogacz M, Winzi M, Chakraborty D, Theis M, Singh S, Ciotta G, Poser I, Roguev A, Chu Wai K, et al. 2015. Systems analyses reveal shared and diverse attributes of Oct4 regulation in pluripotent cells. Cell Systems 1: 141-151.

Elling U, Taubenschmid J, Wirnsberger G, O'Malley R, Demers SP, Vanhaelen Q, Shukalyuk AI, Schmauss G, Schramek D, Schnuetgen F, et al. 2011. Forward and reverse genetics through derivation of haploid mouse embryonic stem cells. Cell Stem Cell 9: 563-574.

Evans MJ, Kaufman MH. 1981. Establishment in culture of pluripotential cells from mouse embryos. Nature 292: 154156.

Fazzio TG, Huff JT, Panning B. 2008. An RNAi screen of chromatin proteins identifies Tip60-p400 as a regulator of embryonic stem cell identity. Cell 134: 162-174.

Fire A, Xu S, Montgomery MK, Kostas SA, Driver SE, Mello CC. 1998. Potent and specific genetic interference by double-stranded RNA in Caenorhabditis elegans. Nature 391: 806-811.

$\mathrm{Fu}$ Y, Foden JA, Khayter C, Maeder ML, Reyon D, Joung JK, Sander JD. 2013. High-frequency off-target mutagenesis induced by CRISPR-Cas nucleases in human cells. Nat Biotechnol 31: $822-826$.

Fu Y, Sander JD, Reyon D, Cascio VM, Joung JK. 2014. Improving CRISPR-Cas nuclease specificity using truncated guide RNAs. Nat Biotechnol 32: 279-284.

Gafni O, Weinberger L, Mansour AA, Manor YS, Chomsky E, Ben-Yosef D, Kalma Y, Viukov S, Maza I, Zviran A, et al. 2013. Derivation of novel human ground state naive pluripotent stem cells. Nature 504: 282-286.

Gayle S, Pan Y, Landrette S, Xu T. 2015. piggyBac insertional mutagenesis screen identifies a role for nuclear RHOA in human ES cell differentiation. Stem Cell Reports 4: 926-938.
Gilbert LA, Horlbeck MA, Adamson B, Villalta JE, Chen Y, Whitehead EH, Guimaraes C, Panning B, Ploegh HL, Bassik $\mathrm{MC}$, et al. 2014. Genome-scale CRISPR-mediated control of gene repression and activation. Cell 159: 647-661.

Gingold JA, Fidalgo M, Guallar D, Lau Z, Sun Z, Zhou H, Faiola F, Huang X, Lee DF, Waghray A, et al. 2014. A genome-wide RNAi screen identifies opposing functions of Snail and Snai2 on the Nanog dependency in reprogramming. Mol Cell 56: $140-152$.

Gonzalez R, Jennings LL, Knuth M, Orth AP, Klock HE, Ou W, Feuerhelm J, Hull MV, Koesema E, Wang Y, et al. 2010. Screening the mammalian extracellular proteome for regulators of embryonic human stem cell pluripotency. Proc Natl Acad Sci 107: 3552-3557.

Gonzales KA, Liang H, Lim YS, Chan YS, Yeo JC, Tan CP, Gao B, Le B, Tan ZY, Low KY, et al. 2015. Deterministic restriction on pluripotent state dissolution by cell-cycle pathways. Cell 162: 564-579.

Guilinger JP, Thompson DB, Liu DR. 2014. Fusion of catalytically inactive Cas9 to FokI nuclease improves the specificity of genome modification. Nat Biotechnol 32: 577-582.

Guo G, Smith A. 2010. A genome-wide screen in EpiSCs identifies $\mathrm{Nr} 5 \mathrm{a}$ nuclear receptors as potent inducers of ground state pluripotency. Development 137: 3185-3192.

Guo G, Huang Y, Humphreys P, Wang X, Smith A. 2011. A PiggyBac-based recessive screening method to identify pluripotency regulators. PLoS One 6: e18189.

Hartwell LH. 1967. Macromolecule synthesis in temperaturesensitive mutants of yeast. J Bacteriol 93: 1662-1670.

Hsu PD, Scott DA, Weinstein JA, Ran FA, Konermann S, Agarwala V, Li Y, Fine EJ, Wu X, Shalem O, et al. 2013. DNA targeting specificity of RNA-guided Cas9 nucleases. Nat Biotechnol 31: 827-832.

$\mathrm{Hu}$ G, Kim J, Xu Q, Leng Y, Orkin SH, Elledge SJ. 2009. A genome-wide RNAi screen identifies a new transcriptional module required for self-renewal. Genes Dev 23: 837848 .

Huch M, Dorrell C, Boj SF, van Es JH, Li VS, van de Wetering M, Sato T, Hamer K, Sasaki N, Finegold MJ, et al. 2013. In vitro expansion of single $\mathrm{Lgr}^{+}$liver stem cells induced by Wnt-driven regeneration. Nature 494: 247-250.

Ivanova N, Dobrin R, Lu R, Kotenko I, Levorse J, DeCoste C, Schafer X, Lun Y, Lemischka IR. 2006. Dissecting self-renewal in stem cells with RNA interference. Nature 442: $533-538$.

Jorgensen EM, Mango SE. 2002. The art and design of genetic screens: Caenorhabditis elegans. Nat Rev Genet 3: 356-369.

Kagey MH, Newman JJ, Bilodeau S, Zhan Y, Orlando DA, van Berkum NL, Ebmeier CC, Goossens J, Rahl PB, Levine SS, et al. 2010. Mediator and cohesin connect gene expression and chromatin architecture. Nature 467: 430-435.

Koike-Yusa H, Li Y, Tan EP, Velasco-Herrera Mdel C, Yusa K. 2014. Genome-wide recessive genetic screening in mammalian cells with a lentiviral CRISPR-guide RNA library. Nat Biotechnol 32: 267-273.

Konermann S, Brigham MD, Trevino AE, Joung J, Abudayyeh OO, Barcena C, Hsu PD, Habib N, Gootenberg JS, Nishimasu H, et al. 2015. Genome-scale transcriptional activation by an engineered CRISPR-Cas9 complex. Nature 517: $583-$ 588.

Kuscu C, Arslan S, Singh R, Thorpe J, Adli M. 2014. Genomewide analysis reveals characteristics of off-target sites bound by the Cas9 endonuclease. Nat Biotechnol 32: 677-683.

Lancaster MA, Knoblich JA. 2014. Organogenesis in a dish: Modeling development and disease using organoid technologies. Science 345: 1247125.

Lancaster MA, Renner M, Martin CA, Wenzel D, Bicknell LS, Hurles ME, Homfray T, Penninger JM, Jackson AP, Knoblich JA. 2013. Cerebral organoids model human brain development and microcephaly. Nature 501: 373-379.

Leeb M, Dietmann S, Paramor M, Niwa H, Smith A. 2014. Genetic exploration of the exit from self-renewal using haploid embryonic stem cells. Cell Stem Cell 14: 385-393. 
Li Z, Rana TM. 2012. A kinase inhibitor screen identifies smallmolecule enhancers of reprogramming and iPS cell generation. Nat Commun 3: 1085.

Liu D, Yang X, Yang D, Songyang Z. 2000. Genetic screens in mammalian cells by enhanced retroviral mutagens. Oncogene 19: $5964-5972$.

Mali P, Yang L, Esvelt KM, Aach J, Guell M, DiCarlo JE, Norville JE, Church GM. 2013. RNA-guided human genome engineering via Cas9. Science 339: 823-826.

Martin GR. 1981. Isolation of a pluripotent cell line from early mouse embryos cultured in medium conditioned by teratocarcinoma stem cells. Proc Natl Acad Sci 78: 76347638 .

Meacham CE, Ho EE, Dubrovsky E, Gertler FB, Hemann MT. 2009. In vivo RNAi screening identifies regulators of actin dynamics as key determinants of lymphoma progression. Nat Genet 41: 1133-1137.

Meacham CE, Lawton LN, Soto-Feliciano YM, Pritchard JR, Joughin BA, Ehrenberger T, Fenouille N, Zuber J, Williams RT, Young RA, et al. 2015. A genome-scale in vivo loss-offunction screen identifies Phf6 as a lineage-specific regulator of leukemia cell growth. Genes Dev 29: 483-488.

Monfort A, Di Minin G, Postlmayr A, Freimann R, Arieti F, Thore S, Wutz A. 2015. Identification of Spen as a crucial factor for Xist function through forward genetic screening in haploid embryonic stem cells. Cell Rep 12: 554-561.

Nichols J, Smith A. 2009. Naive and primed pluripotent states. Cell Stem Cell 4: 487-492.

Niwa H, Burdon T, Chambers I, Smith A. 1998. Self-renewal of pluripotent embryonic stem cells is mediated via activation of STAT3. Genes Dev 12: 2048-2060.

Novick P, Field C, Schekman R. 1980. Identification of 23 complementation groups required for post-translational events in the yeast secretory pathway. Cell 21: 205-215.

Nusslein-Volhard C, Wieschaus E. 1980. Mutations affecting segment number and polarity in Drosophila. Nature 287: $795-801$.

Pardo-Martin C, Chang TY, Koo BK, Gilleland CL, Wasserman SC, Yanik MF. 2010. High-throughput in vivo vertebrate screening. Nat Methods 7: 634-636.

Patton EE, Zon LI. 2001. The art and design of genetic screens: Zebrafish. Nat Rev Genet 2: 956-966.

Pereira DA, Williams JA. 2007. Origin and evolution of high throughput screening. Br J Pharmacol 152: 53-61.

Qin H, Diaz A, Blouin L, Lebbink RJ, Patena W, Tanbun P, LeProust EM, McManus MT, Song JS, Ramalho-Santos M. 2014. Systematic identification of barriers to human iPSC generation. Cell 158: 449-461.

Ran FA, Hsu PD, Lin CY, Gootenberg JS, Konermann S, Trevino AE, Scott DA, Inoue A, Matoba S, Zhang Y, et al. 2013. Double nicking by RNA-guided CRISPR Cas9 for enhanced genome editing specificity. Cell 154: 1380-1389.

Rudalska R, Dauch D, Longerich T, McJunkin K, Wuestefeld T, Kang TW, Hohmeyer A, Pesic M, Leibold J, von Thun A, et al. 2014. In vivo RNAi screening identifies a mechanism of sorafenib resistance in liver cancer. Nat Med 20: 1138 1146.

Samavarchi-Tehrani P, Golipour A, David L, Sung HK, Beyer TA, Datti A, Woltjen K, Nagy A, Wrana JL. 2010. Functional genomics reveals a BMP-driven mesenchymal-to-epithelial transition in the initiation of somatic cell reprogramming. Cell Stem Cell 7: 64-77.

Sato T, Vries RG, Snippert HJ, van de Wetering M, Barker N, Stange DE, van Es JH, Abo A, Kujala P, Peters PJ, et al. 2009. Single Lgr5 stem cells build crypt-villus structures in vitro without a mesenchymal niche. Nature 459: 262-265

Schaniel C, Ang YS, Ratnakumar K, Cormier C, James T, Bernstein E, Lemischka IR, Paddison PJ. 2009. Smarcc1/Baf155 couples self-renewal gene repression with changes in chromatin structure in mouse embryonic stem cells. Stem Cells 27: 2979-2991

Schramek D, Sendoel A, Segal JP, Beronja S, Heller E, Oristian D, Reva B, Fuchs E. 2014. Direct in vivo RNAi screen unveils myosin IIa as a tumor suppressor of squamous cell carcinomas. Science 343: 309-313.

Shalem O, Sanjana NE, Hartenian E, Shi X, Scott DA, Mikkelsen TS, Heckl D, Ebert BL, Root DE, Doench JG, et al. 2014. Genome-scale CRISPR-Cas9 knockout screening in human cells. Science 343: 84-87.

Stadtfeld M, Maherali N, Breault DT, Hochedlinger K. 2008. Defining molecular cornerstones during fibroblast to iPS cell reprogramming in mouse. Cell Stem Cell 2: 230-240.

St Johnston D. 2002. The art and design of genetic screens: Drosophila melanogaster. Nat Rev Genet 3: 176-188.

Takahashi K, Yamanaka S. 2006. Induction of pluripotent stem cells from mouse embryonic and adult fibroblast cultures by defined factors. Cell 126: 663-676.

Takahashi K, Tanabe K, Ohnuki M, Narita M, Ichisaka T, Tomoda K, Yamanaka S. 2007. Induction of pluripotent stem cells from adult human fibroblasts by defined factors. Cell 131: 861-872.

Takashima Y, Guo G, Loos R, Nichols J, Ficz G, Krueger F, Oxley D, Santos F, Clarke J, Mansfield W, et al. 2014. Resetting transcription factor control circuitry toward ground-state pluripotency in human. Cell 158: 1254-1269.

Takebe T, Sekine K, Enomura M, Koike H, Kimura M, Ogaeri T, Zhang RR, Ueno Y, Zheng YW, Koike N, et al. 2013. Vascularized and functional human liver from an iPSC-derived organ bud transplant. Nature 499: 481-484.

Tesar PJ, Chenoweth JG, Brook FA, Davies TJ, Evans EP, Mack DL, Gardner RL, McKay RD. 2007. New cell lines from mouse epiblast share defining features with human embryonic stem cells. Nature 448: 196-199.

Theunissen TW, Powell BE, Wang H, Mitalipova M, Faddah DA, Reddy J, Fan ZP, Maetzel D, Ganz K, Shi L, et al. 2014. Systematic identification of culture conditions for induction and maintenance of naive human pluripotency. Cell Stem Cell 15: 471-487.

Thomson JA, Itskovitz-Eldor J, Shapiro SS, Waknitz MA, Swiergiel JJ, Marshall VS, Jones JM. 1998. Embryonic stem cell lines derived from human blastocysts. Science 282: $1145-1147$.

Tsai SQ, Wyvekens N, Khayter C, Foden JA, Thapar V, Reyon D, Goodwin MJ, Aryee MJ, Joung JK. 2014. Dimeric CRISPR RNA-guided FokI nucleases for highly specific genome editing. Nat Biotechnol 32: 569-576.

van de Wetering M, Francies HE, Francis JM, Bounova G, Iorio F, Pronk A, van Houdt W, van Gorp J, Taylor-Weiner A, Kester L, et al. 2015. Prospective derivation of a living organoid biobank of colorectal cancer patients. Cell 161: 933-945.

Walsh AJ, Cook RS, Sanders ME, Aurisicchio L, Ciliberto G, Arteaga CL, Skala MC. 2014. Quantitative optical imaging of primary tumor organoid metabolism predicts drug response in breast cancer. Cancer Res 74: 5184-5194.

Wang T, Wei JJ, Sabatini DM, Lander ES. 2014. Genetic screens in human cells using the CRISPR-Cas9 system. Science 343: $80-84$.

Ware CB, Nelson AM, Mecham B, Hesson J, Zhou W, Jonlin EC, Jimenez-Caliani AJ, Deng X, Cavanaugh C, Cook S, et al. 2014. Derivation of naive human embryonic stem cells. Proc Natl Acad Sci 111: 4484-4489.

Westerman BA, Braat AK, Taub N, Potman M, Vissers JH, Blom M, Verhoeven E, Stoop H, Gillis A, Velds A, et al. 2011. A genome-wide RNAi screen in mouse embryonic stem cells identifies Mp1 as a key mediator of differentiation. J Exp Med 208: 2675-2689.

Wuestefeld T, Pesic M, Rudalska R, Dauch D, Longerich T, Kang TW, Yevsa T, Heinzmann F, Hoenicke L, Hohmeyer A, et al. 2013. A direct in vivo RNAi screen identifies MKK4 as a key regulator of liver regeneration. Cell 153: $389-401$

Xu C, Rosler E, Jiang J, Lebkowski JS, Gold JD, O’Sullivan C, Delavan-Boorsma K, Mok M, Bronstein A, Carpenter MK. 2005. Basic fibroblast growth factor supports undifferentiated human embryonic stem cell growth without conditioned medium. Stem Cells 23: 315-323. 
Yang SH, Kalkan T, Morrisroe C, Smith A, Sharrocks AD. 2012. A Genome-wide RNAi screen reveals MAP kinase phosphatases as key ERK pathway regulators during embryonic stem cell differentiation. PLoS Genet 8: e1003112.

Yang CS, Chang KY, Rana TM. 2014. Genome-wide functional analysis reveals factors needed at the transition steps of induced reprogramming. Cell Rep 8: 327-337.

Yang BX, El Farran CA, Guo HC, Yu T, Fang HT, Wang HF, Schlesinger S, Seah YF, Goh GY, Neo SP, et al. 2015. Systematic identification of factors for provirus silencing in embryonic stem cells. Cell 163: 230-245.

Ying QL, Nichols J, Chambers I, Smith A. 2003. BMP induction of Id proteins suppresses differentiation and sustains embry- onic stem cell self-renewal in collaboration with STAT3. Cell 115: $281-292$.

Ying QL, Wray J, Nichols J, Batlle-Morera L, Doble B, Woodgett J, Cohen P, Smith A. 2008. The ground state of embryonic stem cell self-renewal. Nature 453: 519-523.

Zender L, Xue W, Zuber J, Semighini CP, Krasnitz A, Ma B, Zender P, Kubicka S, Luk JM, Schirmacher P, et al. 2008. An oncogenomics-based in vivo RNAi screen identifies tumor suppressors in liver cancer. Cell 135: 852-864.

Zhong C, Yin Q, Xie Z, Bai M, Dong R, Tang W, Xing YH, Zhang H, Yang S, Chen LL, et al. 2015. CRISPR-Cas9-mediated genetic screening in mice with haploid embryonic stem cells carrying a guide RNA library. Cell Stem Cell 17: 221-232. 


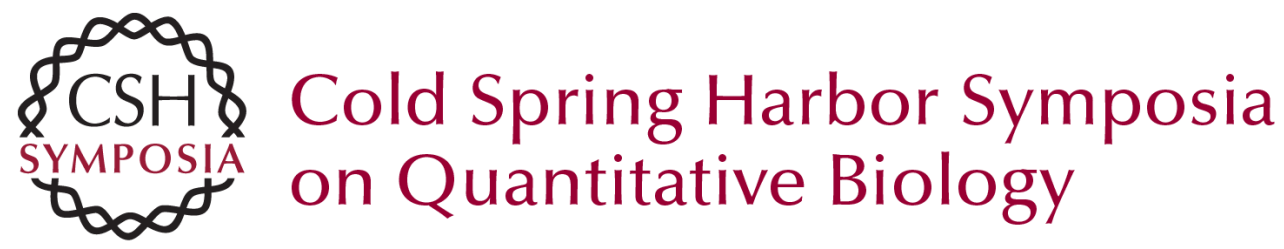

\section{Biological Networks Governing the Acquisition, Maintenance, and Dissolution of Pluripotency: Insights from Functional Genomics Approaches}

Kevin Andrew Uy Gonzales and Huck-Hui Ng

Cold Spring Harb Symp Quant Biol 2015 80: 189-198 originally published online November 18, 2015

Access the most recent version at doi:10.1101/sqb.2015.80.027326

$\begin{array}{ll}\text { References } & \text { This article cites } 91 \text { articles, } 18 \text { of which can be accessed free at: } \\ \text { http://symposium.cshlp.org/content/80/189.full.html\#ref-list-1 }\end{array}$

License

Email Alerting Receive free email alerts when new articles cite this article - sign up in Service the box at the top right corner of the article or click here. 